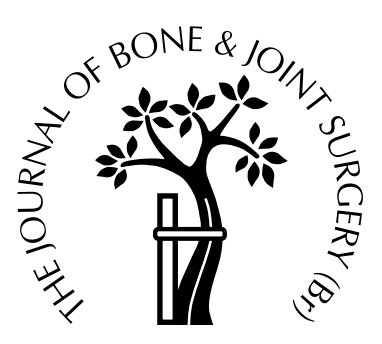

\title{
Loosening of the cup after low-friction arthroplasty in patients with acetabular protrusion
}

THE IMPORTANCE OF THE POSITION OF THE CUP

E. Garcia-Cimbrelo, A. Diaz-Martin, R. Madero, L. Munera

From the Hospital la Paz, Universidad Autónoma de Madrid, Spain

B etween 1972 and 1990, we performed 168 primary low-friction arthroplasties in 125 patients with acetabular protrusion. Twelve hips were lost to follow-up within eight years and eight which became infected were excluded from the final study. Of the 148 hips remaining, 62 with a mild protrusion were classified as group 1, 54 with moderate or severe protrusion as group 2 and, after 1985, 32 with moderate and severe protrusion which required bone grafts as group 3. The mean follow-up was 18.3 years (3 to 24) for group 1, 17.4 years (8 to 22) for group 2 and ten years (8 to 13) for group 3.

There were 31 revisions of the cup, 12 in group 1 and 19 in group 2. According to the Kaplan-Meier analysis the overall rates at 20 years were $21 \pm$ $10.79 \%$ in group 1 and $37 \pm 11.90 \%$ in group 2 . There have been 43 radiological loosenings: 22 in group 1, 21 in group 2 and none so far in group 3, at ten years. The overall loosening rates at 20 years were $42 \pm$ $14.76 \%$ in group 1 and $49 \pm 19.50 \%$ in group 2 . The grafts were well incorporated in all group-3 hips, and the bone structure appeared normal after one year.

The distance between the centre of the head of the femoral prosthesis and the approximate true centre of the femoral head was less in group 3 than in groups 1 and $2(\mathbf{p}<0.01)$. According to the Cox proportional-hazards regression this was the single most important factor in loosening of the cup (odds ratio $1.11 ; 95 \%$ CI 1.05 to $1.18 / \mathrm{mm}$ ). Better results were obtained in moderate and severe protrusions

E. Garcia-Cimbrelo, MD, Consultant Orthopaedic Surgeon

A. Diaz-Martin, MD, Orthopaedic Surgeon

L. Munuera, MD, Chairman of Orthopaedic and Trauma Surgery

Department of Orthopaedics

R. Madero, MS, Biostatistician

Section of Biostatistics

Hospital la Paz, Paseo de la Castellana 261, 28046 Madrid, Spain.

Correspondence should be sent to Dr E. Garcia-Cimbrelo at Pez Austral 13, $5^{\circ} \mathrm{A}, 28007$ Madrid, Spain.

(C)2000 British Editorial Society of Bone and Joint Surgery 0301-620X/00/19796\$2.00

108 reconstructed with bone grafting than in hips with mild protrusion which were not grafted.

J Bone Joint Surg [Br] 2000;82-B:108-15.

Received 11 January 1999; Accepted after revision 23 June 1999

Deficient bone stock in patients with acetabular protrusion compromises the fixation of the cup in total hip replacement. Reinforcement of the medial wall and placement of the prosthesis in the correct anatomical position, using cement alone, or with mesh or bone graft, have been advocated. $^{1-5}$ A thin medial wall may, however, suffer thermal necrosis during cement polymerisation resulting in further migration medially. ${ }^{6-8}$ Since McCollum et al ${ }^{4}$ first recommended autologous bone graft to fill the medial defect in the acetabulum, several authors have used this technique. $^{1-3,6,9}$

We have analysed the long-term results of low-friction arthroplasty (LFA) in relation to the position of the cup in patients with acetabular protrusion, treated either with or without cancellous bone graft. A Cox proportional-hazards regression model was used to test a number of variables which may have influenced the rate of loosening of the cup and to assess their relative prognostic significance.

\section{Patients and Methods}

We reviewed all patients with acetabular protrusion treated with LFA between March 1982 and December 1990. A minimum time of eight years from the operation was required for inclusion in the study. Revisions for loosening were included regardless of the length of follow-up.

We performed 168 LFAs in 125 patients in this period; 12 hips in ten patients were excluded because they were lost to follow-up within eight years of operation, leaving 156 LFAs in 115 patients (47 men and 68 women). We also excluded eight hips from the follow-up study because of deep infection. The remaining 148 LFAs (107 patients) were assessed. A total of 15 patients had died after a mean of 15.7 years (10 to 20 ). All had been followed up until the time of death.

Protrusion was graded according to the criteria of SoteloGarza and Charnley. ${ }^{5}$ The rim of the pelvis, taken as a projection of the upper margin of the pubic ramus, is used

THE JOURNAL OF BONE AND JOINT SURGERY 
Table I. Details of the 148 patients who were treated with arthroplasty for acetabular protrusion

\begin{tabular}{|c|c|c|c|c|}
\hline & Group 1 & Group 2 & Group 3 & Total \\
\hline Number of patients & 62 & 54 & 32 & 148 \\
\hline Mean age in years (range) & $54(19$ to 71$)$ & 57 (17 to 72$)$ & $50(22$ to 75$)$ & 54 (17 to 75$)$ \\
\hline Mean weight in $\mathrm{kg}$ (range) & 66 (43 to 75$)$ & 68 (50 to 80$)$ & 64 (47 to 76$)$ & 66 (43 to 80$)$ \\
\hline $\begin{array}{l}\text { Gender } \\
\text { Male } \\
\text { Female }\end{array}$ & $\begin{array}{l}31 \\
31\end{array}$ & $\begin{array}{l}17 \\
37\end{array}$ & $\begin{array}{l}12 \\
20\end{array}$ & $\begin{array}{l}60 \\
88\end{array}$ \\
\hline $\begin{array}{l}\text { Protrusion } \\
\text { Grade I } \\
\text { II } \\
\text { III }\end{array}$ & $\begin{array}{l}62 \\
- \\
-\end{array}$ & $\begin{array}{l}- \\
34 \\
20\end{array}$ & $\begin{array}{l}- \\
10 \\
22\end{array}$ & $\begin{array}{l}62 \\
44 \\
42\end{array}$ \\
\hline $\begin{array}{l}\text { Primary diagnosis } \\
\text { Rheumatoid arthritis } \\
\text { Primary osteoarthritis } \\
\text { Ankylosing spondylitis } \\
\text { Lupus erythematosus } \\
\text { Paget's disease }\end{array}$ & $\begin{array}{r}32 \\
14 \\
14 \\
1 \\
1\end{array}$ & $\begin{array}{r}30 \\
14 \\
7 \\
2 \\
1\end{array}$ & $\begin{array}{r}17 \\
9 \\
4 \\
2 \\
-\end{array}$ & $\begin{array}{r}79 \\
37 \\
25 \\
5 \\
2\end{array}$ \\
\hline Mean follow-up in years (range) & 18.3 (3 to 24$)$ & 17.3 ( 8 to 22$)$ & $10(8$ to 13$)$ & 16 (3 to 24 ) \\
\hline
\end{tabular}

as a reference and the protrusion graded as follows: I, mild with the hips displaced from 1 to $5 \mathrm{~mm}$; II, moderate with the hips displaced from 6 to $15 \mathrm{~mm}$; and III, severe with the hips displaced more than $15 \mathrm{~mm}$.

Patients were classified into three groups. Group 1 consisted of patients (62 hips) with grade-I hips treated by simple LFA $(n=62)$ and group 2 of patients (54 hips) with grade-II and grade-III hips, treated by simple LFA. Since 1985 patients (32 hips) with grade-II and grade-III hips have been treated by LFA and spongious bone grafts; these constitute group 3. The age, weight, gender, grade of protrusion, diagnosis and period of follow-up until revision or the latest evaluation for each group are listed in Table I.

Operative technique. All operations were carried out using the same technique with a lateral approach and trochanteric osteotomy. In difficult cases, the neck of the femur was divided and the head extracted in retrograde fashion. ${ }^{5}$ The acetabulum was not deepened and a reamer was only used to assess the size of the acetabular component. No pilot hole was made. ${ }^{5}$ The standard Charnley prosthesis was used comprising a hemispherical socket of ultra-highmolecular-weight polyethylene and a stainless-steel femoral stem with a $22.25 \mathrm{~mm}$ diameter head (Chas F Thackray, Leeds, UK). The polymethylmethacrylate cement used for fixation was radiopaque CMW1 (CMW Laboratories, Devon, UK). Cement was packed into the acetabular cavity using thumb pressure. Since 1985, we have used an Ogee flanged cup (Chas F Thackray) together with thin slices of cancellous bone from the autogenous femoral head, about $2 \mathrm{~mm}$ in thickness, taken with an oscillating saw after the hip has been dislocated. These slices were moulded against the medial wall ${ }^{5,6}$ and combined with cement in moderate or severe acetabular protrusion. All patients were given antibiotic and antithrombotic prophylaxis. After surgery, they used crutches for eight weeks.

Clinical assessment. All patients were examined immediately after operation, six months later, and then yearly.
Clinical evaluation included assessment of pain, function and range of movement according to the Merle D'Aubigné and Postel scale (levels 1 to 6 ). ${ }^{10}$ Clinical failure was defined as revision of the acetabular component, the indication for revision, or pain of level 4 or worse. The number of hips assessed in each period of follow-up is shown in Table I.

Radiological assessment. Standard anteroposterior (AP) radiographs of the pelvis were taken. The patient was positioned supine, with the feet together. The x-ray tube was placed over the symphysis pubis, 1 metre from, and perpendicular to the table. Variations in magnification were corrected using the diameter of the head of the femoral component as an internal reference. The acetabular angle was described as neutral $\left(40^{\circ}\right.$ to $\left.50^{\circ}\right)$, horizontal $\left(<40^{\circ}\right)$, or vertical $\left(>50^{\circ}\right) .{ }^{11}$ The distribution of cement around the socket was classified according to DeLee and Charnley. ${ }^{12}$ At follow-up each radiograph was analysed and compared with the previous views by the same observer (ADM) who was blinded to the operative findings.

The postoperative position of the cup was determined according to Ranawat, Dorr and Inglis. ${ }^{13}$ The true acetabular region (TAR) was the area enclosed by a rightangled triangle (Fig. 1) with the height and width equal to $20 \%$ of the height of the pelvis on the AP radiograph. ${ }^{13,14}$ The inferomedial corner of the TAR was $5 \mathrm{~mm}$ lateral to the intersection of the Köhler line with the radiological teardrop (Fig. 1). In a normal hip the superior border of the triangle will pass through the upper part of the subchondral bone of the acetabulum. The hypotenuse of this triangle represents the diameter of the mouth of the acetabulum. ${ }^{13}$ The mid-point of the hypotenuse coincides with the approximate centre of the femoral head (AFHC) and is the centre of rotation of the hip. ${ }^{14}$ The AFHC was used as the reference point to measure distances between the centre of rotation of the normal hip and the centre of the prosthetic femoral head (CPFH). These distances were recorded for 


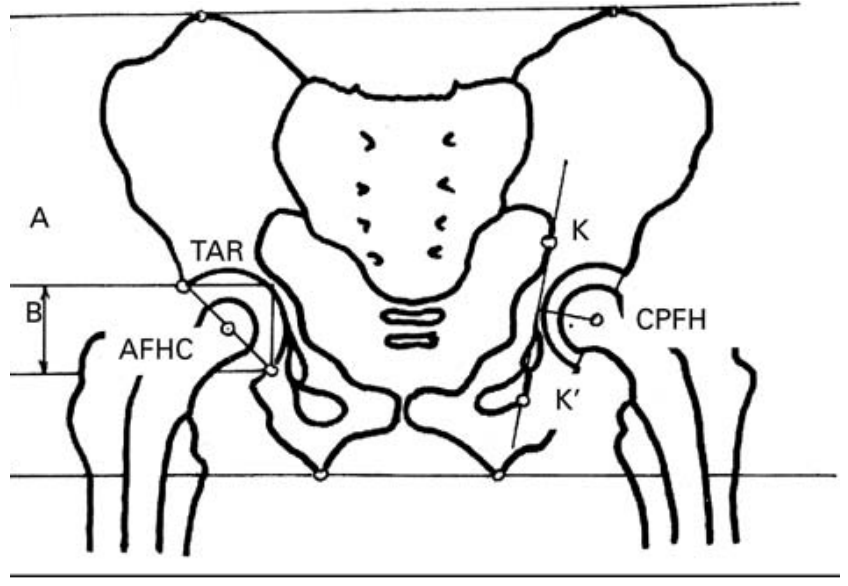

Fig. 1

Diagram showing the method for postoperative measurement of the cup. The true acetabular region (TAR) is measured as the area enclosed by a right-angled triangle, with the height and width (B) equal to $20 \%$ of the height of the pelvis (A). The mid-point of the hypotenuse of the triangle is defined as the approximate centre of the femoral head (AFHC) and represents the normal centre of rotation of the hip. CPFH indicates the centre of the prosthetic femoral head, and KK, the Köhler line which is drawn from the medial border of the ilium to the medial border of the ischium.

each hip. If the CPFH was initially positioned superior or lateral to the TAR, the cup was defined as being outside the TAR (Fig. 1).

Any radiolucent line at the cement-bone interface adjacent to the acetabular component, regardless of thickness, was classified according to the system of Hodgkinson, Shelley and Wroblewski ${ }^{15}$ and Hodgkinson et al. ${ }^{16}$ Twodimensional linear wear of the acetabular component was assessed as described by Livermore, Ilstrup and Morrey. ${ }^{17}$

The radiological appearance of bone graft is difficult to interpret, and criteria for assessing its incorporation have yet to be standardised. ${ }^{18}$ We subjectively determined the density of the graft compared with the iliac bone adjacent to the joint, the appearance of the graft-host junction, the presence of trabecular continuity between the graft and the acetabular bone, and any change in position of the cup. 9,18 Any change in radiodensity within the graft was considered indicative of primary healing, a confluent area of radiolucency within the graft was equated with localised resorption of the graft, and stress-oriented trabeculae within the graft were judged as evidence of trabecular remodelling or secondary healing. ${ }^{19}$ Resorption of less than one-third of the graft was considered as minor, between one-third and one-half of the graft as moderate, and more than one-half of the graft as major. ${ }^{20}$

Definition of failure. The acetabular component was considered to have migrated when there had been a change of more than $5^{\circ}$ in the acetabular angle, more than $3 \mathrm{~mm}$ either in the height of the cup, as measured from the ipsilateral teardrop, or in the horizontal distance of the cup, measured from the centre of the femoral head to the Köhler line. ${ }^{16}$ The acetabular component was considered to show definite loosening when the acetabular cup had migrated (type 4), probable loosening when there was a circumferential radiolucent line in the follow-up radiographs (type 3 ), and possible loosening when a radiolucent line appeared to occupy more than $50 \%$ (but less than 100\%) of the contour of the cup (type 2). ${ }^{15,16}$ Medial protrusion was assessed by measuring the distance from the centre of the femoral head to the Köhler line.

Statistical analysis. Kaplan-Meier survivorship analysis with $95 \%$ confidence intervals $^{21,22}$ was used to estimate the rate of failure. The results were assessed using the MantelCox test to compare the Kaplan-Meier curves. The level of significance was $\mathrm{p}<0.05$. The McNemar test for symmetry and chi-squared tests were also used.

Since the periods of evaluation for the groups were different, a Cox proportional-hazards regression model was done to assess the influence of various factors on the rate of loosening of the acetabular cup. A univariate analysis was applied to each variable together with the rate of loosening using Kaplan-Meier survivorship analysis. The results were compared with the Mantel-Cox test for qualitative data and the univariate regression Cox model for quantitative assessment. Additionally, a Cox proportional-hazards regression model was done for all variables showing a significance of $\mathrm{p}<0.20$ in the previous univariate study. The distance from the CPFH to the Köhler line, the distance from the CPFH to the AFHC, the position of the CPFH inside the TAR, age, gender, preoperative diagnosis, and grade of protrusion were the independent variables used to estimate the odds ratio of loosening of the cup. This procedure identifies those variables which most influence loosening. ${ }^{23-25}$ An analysis of variance (ANOVA) was used to assess the mean distances between the $\mathrm{CPFH}$ and the AFHC in each group.

\section{Results}

Complications. Infection occurred in eight hips (5\%) and these were excluded from the follow-up study; their preoperative diagnoses were rheumatoid arthritis in four, osteoarthritis in two, ankylosing spondylitis in one, and systemic lupus erythematosus in one.

In four hips the infections were 'late'. One, from group 3 , developed major resorption of the bone graft and was diagnosed during a revision operation 40 months after the first procedure. Staphylococcus epidermidis was cultured from the surgical specimen. Other complications including pseudarthrosis of the trochanter in 15 hips, intraoperative fractures of the femur in five, and dislocation in four were successfully treated and the prostheses were retained in these patients.

Operative details. The immediate postoperative position of the cup was assessed by determining the angle of the acetabular cup, the distance from the $\mathrm{CPFH}$ to the Köhler line, the distance from the CPFH to the AFHC, and whether the $\mathrm{CPFH}$ was outside the TAR in each group of hips 
(Table II). A neutral position of the cup was more frequently observed in group $3(\mathrm{p}<0.001)$ than in groups 1 and 2. The distance between the CPFH and the Köhler line was greater in groups 1 and 3 than in group $2(p<0.05)$. The distance between the CPFH and the AFHC was not only less (by approximately $5 \mathrm{~mm}$ ) in group 3 than in groups 1 and $2(\mathrm{p}<0.05)$ but the range of distances was smaller (Fig. 2). The CPFH was inside the TAR more frequently in group 3 than in groups 1 and $2(p<0.001)$.

Clinical data and revisions. There were 31 revisions of the cup, 12 in group $1(21 \pm 10.79 \%$ at 20 years in the Kaplan-Meier analysis), 19 in group $2(37 \pm 11.90 \%$ at the same period of time), and none in group 3 . There was a significant difference in the three groups (Mantel-Cox test, $\mathrm{p}=0.0213)$. The difference for group 3 compared with groups 1 and 2 (Fig. 3) was also significant (Mantel-Cox test, $\mathrm{p}=0.0283$ ). Revisions of the femoral stem were less common with nine occurring in group 1 and 16 in group 2, always associated with revised cups (McNemar symmetry test, $\mathrm{p}=0.01$ ). Clinical assessment before and after operation in all hips which were not revised, showed improvement at all levels in the three groups assessed (Table III). Radiological follow-up. There were 43 definite or probable radiological loosenings, $22(42 \pm 14.76 \%$ at 20 years in the Kaplan-Meier analysis) in group 1, $21(49 \pm 19.50 \%$ after the same period of time) in group 2, and none in group 3 at 12 years. As shown in Figure 4 the difference between the

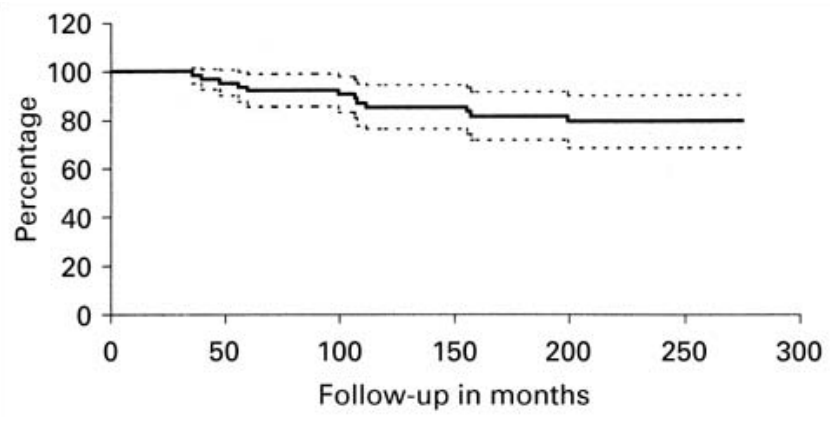

Fig. 3a

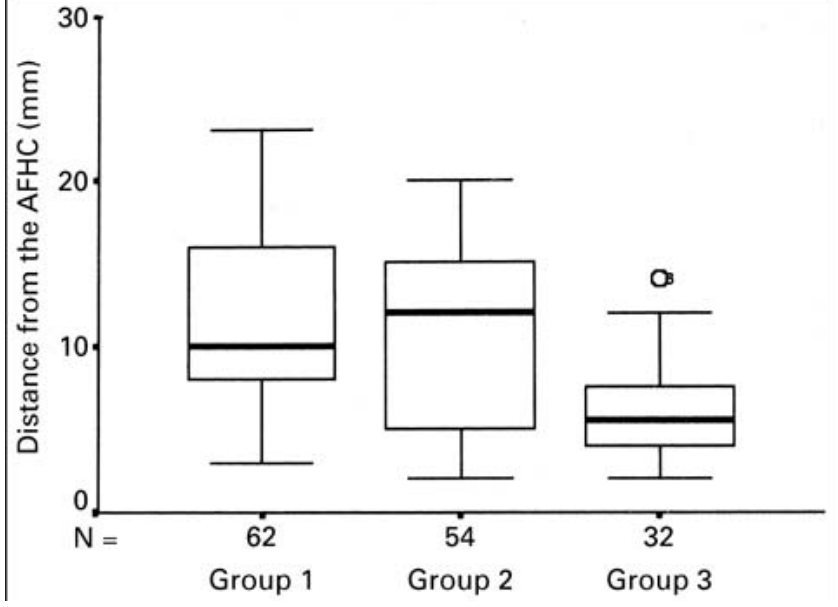

Fig. 2

Box-and-whisker plot showing the distribution of the distance between the $\mathrm{CPFH}$ and the AFHC in each group. The thick horizontal lines represent the median. The lower boundary of the box is the 25th percentile, and the upper boundary is the 75th. The whiskers show the highest and lowest values which are not outliers. An outlier, 'O', is any value more than 1.5 box-lengths from the upper fourth; there was only one (case 6 in group 3).

three groups was significant (Mantel-Cox test, $\mathrm{p}<0.05$ ), with the difference for group 3 compared with groups 1 and 2 also significant (Mantel-Cox test, $\mathrm{p}=0.024$ ). Migration occurred in most of the 43 loose cups. Acetabular angles

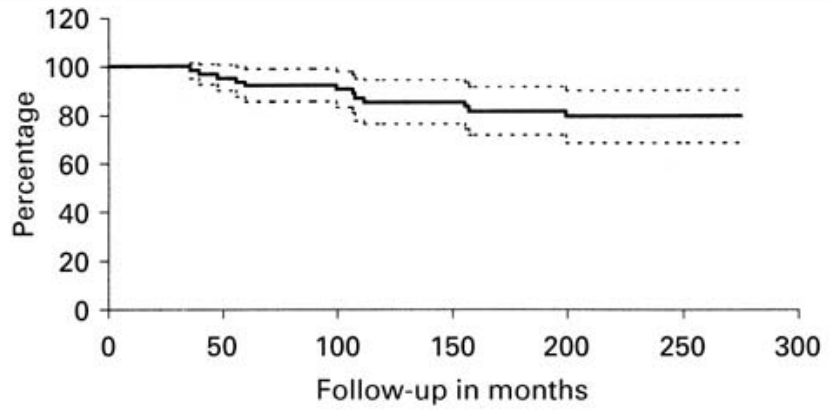

Fig. $3 b$

Graphs showing the Kaplan-Meier cumulative probability of not having revision of the acetabular cup for a) group 1 and b) group 2 . The dotted lines indicate the $95 \%$ CI.

Table II. Postoperative position of the 148 hips

\begin{tabular}{llll}
\hline & Group 1 & Group 2 & Group 3 \\
\hline Number of patients & 62 & 54 & 32 \\
Mean cup angle in degrees & $46(30$ to 62$)$ & $50(35$ to 68$)$ & 45.8 (40 to 50) \\
$\quad$ Neutral & 38 & 30 & 30 \\
$\quad$ Horizontal & 12 & 3 & 2 \\
$\quad$ Vertical & 12 & 21 & - \\
Mean CPFH to Köhler line distance in mm (SD) & $24.9(8.2)$ & $18.6(7.4)$ & $25.3(1.5)$ \\
Mean CPFH to AFHC distance in mm (SD) & $11.5(5.4)$ & $10.68(5.4)$ & $5.9(3.1)$ \\
Mean CPFH placement within TAR & & & \\
$\quad$ Inside & 30 & 30 & 28 \\
$\quad$ Outside & 32 & 24 & 4 \\
\hline
\end{tabular}




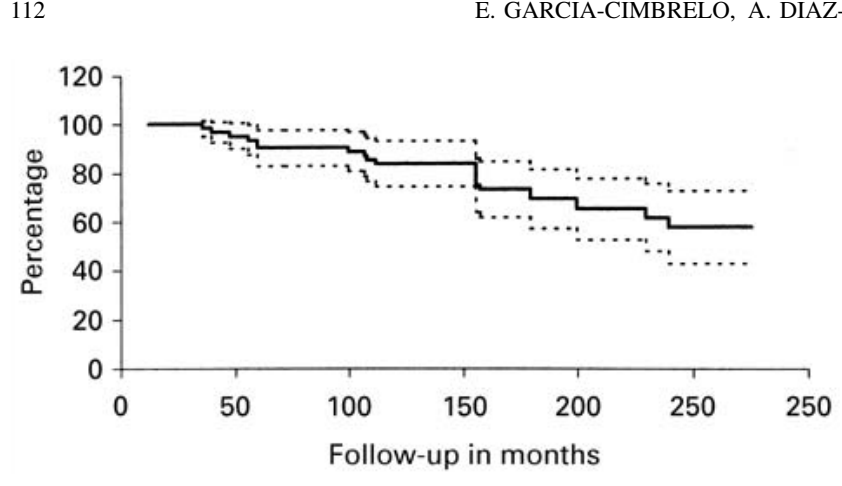

Fig. $4 \mathrm{a}$

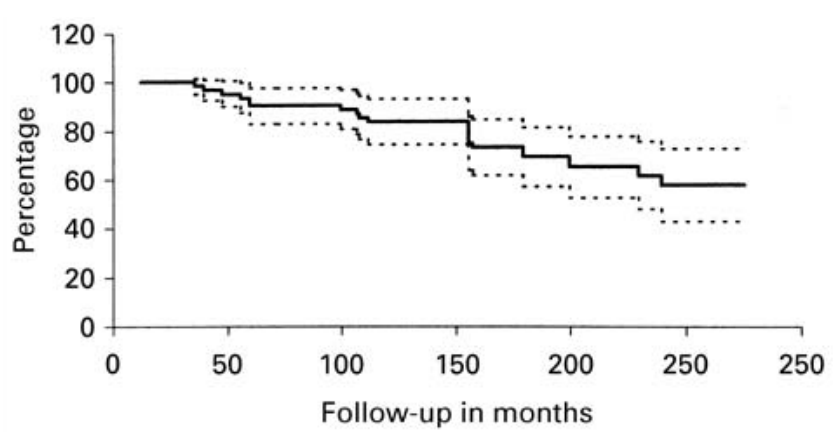

Fig. 4b

Graphs showing the Kaplan-Meier cumulative probability of not having loosening of the cup for a) group 1 and b) group 2 . The dotted lines indicate the $95 \% \mathrm{CI}$.

changed in 17 and 19, vertical migration occurred in ten and 18 , and horizontal migration in nine and 19 of groups 1 and 2 , respectively.

Table III. Mean values for pain, function, and range of hip movement for each group at each follow-up interval according to the Merle D'Aubigné and Postel score ${ }^{10}$

\begin{tabular}{lllll}
\hline & $\begin{array}{l}\text { Number } \\
\text { of hips }\end{array}$ & Pain & Function & $\begin{array}{l}\text { Range of } \\
\text { movement }\end{array}$ \\
\hline Group 1 & & & & \\
$\quad$ Before operation & 62 & 2.15 & 2.3 & 2.4 \\
$\quad 5$ years & 58 & 5.6 & 5.1 & 5.1 \\
10 years & 50 & 5.4 & 5.1 & 5.0 \\
15 years & 38 & 4.9 & 4.8 & 4.8 \\
20 years & 16 & 5.0 & 4.9 & 4.8 \\
Group 2 & & & & \\
$\quad$ Before operation & 54 & 2.3 & 2.3 & 2.3 \\
$\quad 5$ years & 54 & 5.4 & 5.1 & 5.0 \\
10 years & 45 & 5.4 & 5.1 & 5.1 \\
15 years & 29 & 5.2 & 5.0 & 5.1 \\
20 years & 8 & 5.2 & 5.1 & 4.9 \\
Group 3 & & & & \\
Before operation & 32 & 2.2 & 2.3 & 2.3 \\
$\quad$ 5 years & 32 & 5.6 & 5.6 & 5.2 \\
10 years & 24 & 5.6 & 5.6 & 5.2 \\
\hline
\end{tabular}

Demarcation of the cement-bone interface gradually increased in 78 of the 148 hips (53\%) by an amount which varied between the groups. In groups 1 and 2, radiological evidence of migration was seen in 17 of the 82 cups (21\%) in which no demarcation had been detected on the initial postoperative radiograph. It was also evident in ten of the 24 cups with type- 1 demarcation, all seven cups with type2 , and in all three cups with type-3 demarcation. It was uncommon in group 3 (Table IV). All changes in demarcation were to a more severe type (McNemar test for symmetry, $\mathrm{p}<0.00$ ). Loosening of the cup was related to a depth of acetabular wear equal to or greater than $2 \mathrm{~mm}$ (Table V) for the entire series $(\mathrm{p}<0.001)$.

The bone grafts were well incorporated in all group-3 hips. In the immediate postoperative radiographs the cancellous graft appeared less dense than the acetabular bone, but at follow-up the density was seen to increase in comparison with the acetabulum in all the hips after the third month. Trabecular continuity between the graft and the host bone was seen in DeLee and Charnley zones 1 and 3 after one year (Fig. 5). Radiolucent lines were uncommon (Table IV), and no hip showed a change in the position of the cup

Table IV. Progression of radiological demarcation from initial postoperative radiograph to the latest follow-up according to the criteria of Hodgkinson et al ${ }^{15,16}$

\begin{tabular}{|c|c|c|c|c|c|c|c|}
\hline \multirow{2}{*}{\multicolumn{2}{|c|}{$\begin{array}{l}\text { Initial } \\
\text { postoperative } \\
\text { demarcation }\end{array}$}} & \multicolumn{5}{|c|}{ Latest demarcation (number of cups) } & \multirow{3}{*}{$\begin{array}{l}\begin{array}{l}\text { Total } \\
\text { number } \\
\text { of hips }\end{array} \\
62\end{array}$} \\
\hline & & \multirow[t]{2}{*}{ Type 0} & \multirow[t]{2}{*}{ Type 1} & \multirow[t]{2}{*}{ Type 2} & \multirow[t]{2}{*}{ Type 3} & \multirow[t]{2}{*}{ Type 4} & \\
\hline Group & 1 & & & & & & \\
\hline \multirow[t]{4}{*}{ Type } & 0 & 20 & 9 & 2 & 2 & 9 & 42 \\
\hline & 1 & - & 5 & 4 & 2 & 5 & 16 \\
\hline & 2 & - & - & - & - & 3 & 3 \\
\hline & 3 & - & - & - & - & 1 & 1 \\
\hline Group & 2 & & & & & & 54 \\
\hline \multirow[t]{4}{*}{ Type } & 0 & 14 & 11 & 6 & 1 & 8 & 40 \\
\hline & 1 & - & - & 2 & 1 & 5 & 8 \\
\hline & 2 & - & - & - & - & 4 & 4 \\
\hline & 3 & - & - & - & - & 2 & 2 \\
\hline Group & 3 & & & & & & 32 \\
\hline \multirow[t]{4}{*}{ Type } & 0 & 29 & 1 & - & - & - & 30 \\
\hline & 1 & - & 1 & - & - & - & 1 \\
\hline & 2 & - & - & 1 & - & - & 1 \\
\hline & 3 & - & - & - & - & - & 0 \\
\hline
\end{tabular}




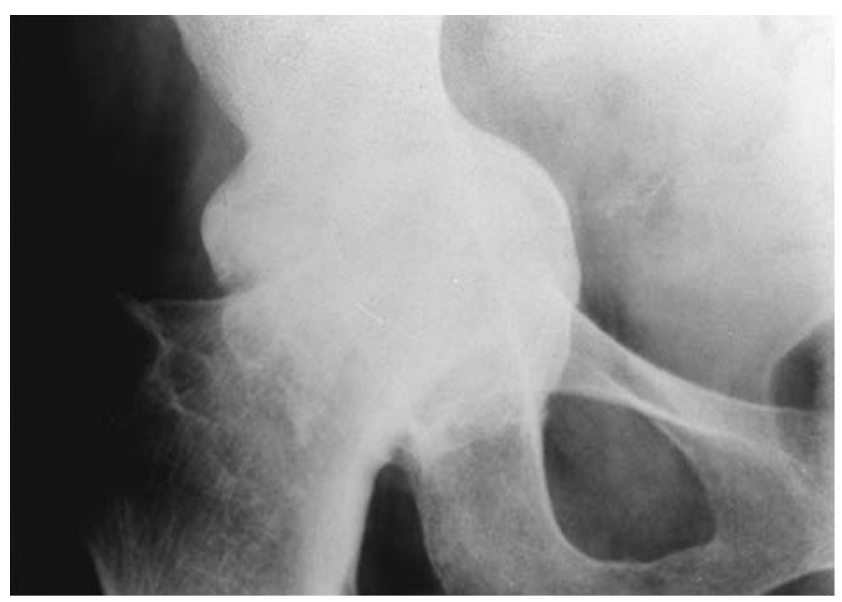

Fig. 5a

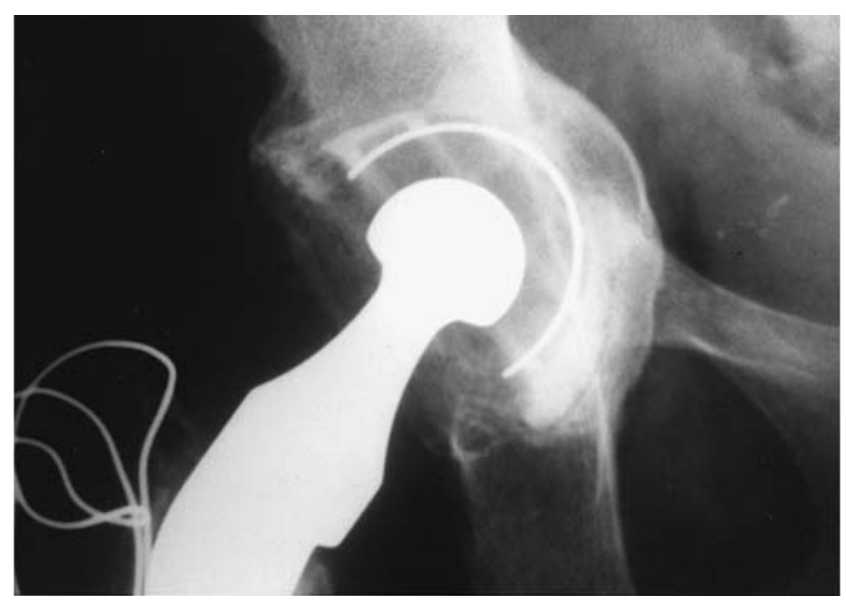

Fig. $5 \mathrm{c}$

Table V. Acetabular linear wear and loosening of the acetabular cup in the different groups at latest follow-up

\begin{tabular}{|c|c|c|c|c|}
\hline & Wea & & & \\
\hline & $<2$ & 2 & $>2$ & number \\
\hline Group 1 & & & & \\
\hline Number of cups & 33 & 24 & 5 & 62 \\
\hline Number of loose cups & 7 & 10 & 5 & 22 \\
\hline Group 2 & & & & \\
\hline Number of cups & 30 & 21 & 3 & 54 \\
\hline Number of loose cups & 8 & 10 & 3 & 21 \\
\hline Group 3 & & & & \\
\hline Number of cups & 29 & 3 & - & 32 \\
\hline Number of loose cups & - & - & - & 0 \\
\hline
\end{tabular}

or resorption of the graft at the latest follow-up.

Statistical analysis. According to the univariate analysis, loosening of the cup was related to the distance between the $\mathrm{CPFH}$ and the AFHC $(\mathrm{p}=0.0002)$, while the association between age $(\mathrm{p}=0.06)$, the position of the $\mathrm{CPFH}$ lying outside the TAR $(\mathrm{p}=0.1559)$, and the distance from the CPFH to the Köhler line $(\mathrm{p}=0.2052)$ was almost as significant (Table VI). The results suggested multiple regres-

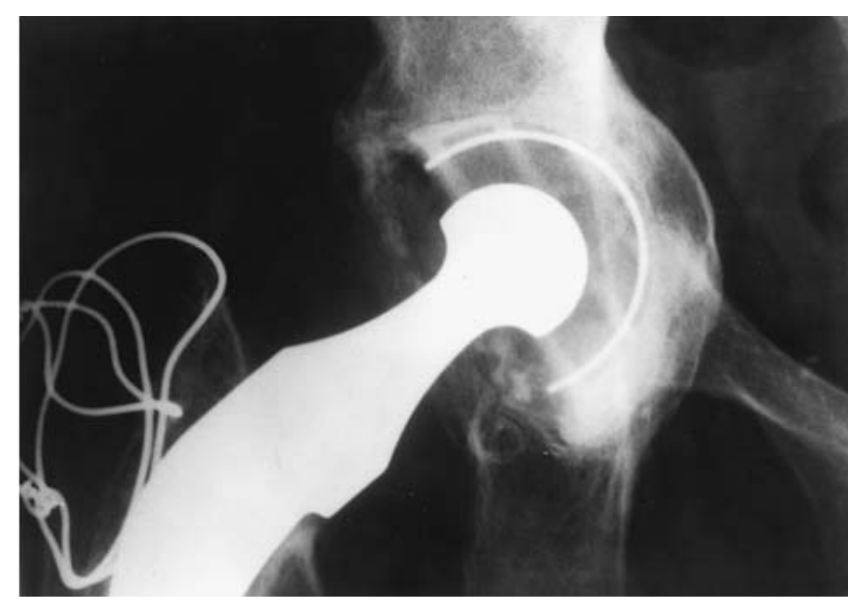

Fig. 5b

Anteroposterior radiographs of a hip with acetabular protrusion in a 54-year-old woman, treated by an arthroplasty with cancellous autograft showing the hip a) before operation and b) three months after when the graft appeared less dense than the acetabular bone, and c) 12 months after the operation when density had increased in comparison with the acetabulum. The normal structure of cancellous bone is visible without resorption.

sion analysis for the following variables; the position of the CPFH in the TAR (inside/outside), the distance from the CPFH to the Köhler line, age, and the distance from the $\mathrm{CPFH}$ to the AFHC. Multivariate analysis identified the distance from the $\mathrm{CPFH}$ to the $\mathrm{AFHC}$ as being associated with loosening (odds ratio $1.11,95 \%$ CI 1.05 to $1.18 / \mathrm{mm}$ ). Thus the risk of loosening is increased 1.11 times $/ \mathrm{mm}$ by the distance from the CPFH to the AFHC. Since this distance in group 3 is approximately $5 \mathrm{~mm}$ less than that in groups 1 and 2, these latter groups have a greater risk for loosening; according to Christensen ${ }^{23}$ that risk is increased 1.72 times (95\% CI 1.61 to 1.82 ) (Table VII).

\section{Discussion}

Severe acetabular protrusion jeopardises the success of fixation of the cup in THR, and early loosening has been reported. ${ }^{26-28}$ As in most other series, rheumatoid arthritis was the usual condition to cause acetabular protrusion ${ }^{1,28}$ (79 in our series) and late infection, probably haematogenous, has been more common in these patients than in those with other diagnoses. ${ }^{29-31}$ We saw eight infected hips 
Table VI. Factors which could affect loosening

\begin{tabular}{|c|c|c|c|}
\hline Factors & Loosening & No loosening & $\begin{array}{l}\text { p value } \\
\text { (Mantel-Cox) }\end{array}$ \\
\hline \multicolumn{4}{|l|}{ CPFH placement within TAR } \\
\hline Outside & 23 & 37 & \multirow{2}{*}{0.1559} \\
\hline Inside & 20 & 68 & \\
\hline \multicolumn{4}{|l|}{ Gender } \\
\hline Male & 14 & 46 & \multirow{2}{*}{$\begin{array}{l}0.1972 \\
(\mathrm{NS})\end{array}$} \\
\hline Female & 29 & 59 & \\
\hline \multicolumn{4}{|l|}{ Primary diagnosis } \\
\hline Rheumatoid arthritis & 25 & 54 & \multirow{5}{*}{$\begin{array}{l}0.6775 \\
\text { (NS) }\end{array}$} \\
\hline Osteoarthritis & 7 & 30 & \\
\hline Ankylosing spondylitis & 8 & 17 & \\
\hline Lupus erythematosus & 2 & 3 & \\
\hline Paget's disease & 1 & 1 & \\
\hline \multicolumn{4}{|l|}{ Protrusion grade } \\
\hline I & 22 & 40 & \multirow{3}{*}{$\begin{array}{l}0.9751 \\
(\mathrm{NS})\end{array}$} \\
\hline II & 12 & 32 & \\
\hline III & 9 & 33 & \\
\hline Mean CPFH to Köhler line distance in mm (SD) & $20.97(8.11)$ & $23.42(7.34)$ & $0.2057^{*}$ \\
\hline Mean CPFH to AFHC distance in $\mathrm{mm}$ (SD) & $12.97(5.5)$ & $8.73(4.9)$ & $0.0002 *$ \\
\hline Age in years $(\mathrm{SD})$ & $51.9(13.8)$ & $55.8(11.3)$ & $0.06^{*}$ \\
\hline
\end{tabular}

* Cox regression univariate

and in four of these the onset of infection was late. Patients, physicians, and dentists must consider the need for antibiotics in the treatment of any infectious disease. ${ }^{31}$

Although Sotelo-Garza and Charnley ${ }^{5}$ found no differences in the successful results using bone graft or cement alone, without correcting the deformity, Jasty and Harris ${ }^{28}$ observed good results in mild protrusion, but poor longterm results in severe protrusion, when cement and wire mesh alone were used. Other series have associated loosening of the cup with inadequate restoration of the anatomical position. ${ }^{1,13,29,32}$ In our series, protrusion progressed in 18 of the 62 group- 1 hips and in 19 of the 54 in group 2. There was no progression of the protrusion in any of the 32 hips in group 3. Better results after LFA were found in hips with moderate and severe protrusion corrected using cancellous graft than in those with mild protrusion using cement alone. In the group using spongious grafts, the distance from the $\mathrm{CPFH}$ to the AFHC was approximately $5 \mathrm{~mm}$ less than in hips in which a graft was not used, even in those with mild protrusion.

Many factors may be responsible for loosening of the cup in acetabular protrusion. The thin medial wall of the protruded acetabulum is often osteoporotic, so that adequate fixation by cement is uncertain, even in mild protrusion. Cancellous bone graft can provide a biological buttress after incorporation and become a substantial acetabulum in which thermal necrosis and osteolysis, which may follow the exothermic curing of acrylic cement, is reduced. ${ }^{6-8}$ Correction to the anatomical position using bone graft is easier in moderate and severe than in mild protrusion. Finite-element analysis of a protruded acetabulum has shown that stress on the medial wall varies directly with medial placement of the cup. ${ }^{33}$ Most authors agree that it is crucial for good long-term results that
Table VII. Univariate analysis of adjusted risk factors for loosening of the cup

\begin{tabular}{ll}
\hline Variable & $\begin{array}{l}\text { Univariate analysis } \\
\text { (odds ratio }(\mathbf{C I}))\end{array}$ \\
\hline CPFH placement within TAR (outside/inside) & $0.65(0.35$ to 1.18$)$ \\
CPFH to Köhler line distance & $0.97(0.94$ to 1.01$)$ \\
CPFH to AFHC distance & $1.12(1.05$ to 1.18$)$ \\
Age & $0.98(0.96$ to 1.00$)$ \\
\hline
\end{tabular}

protrusion be corrected to the anatomical position. $^{1,13,29,33-35}$ Theoretically, the location of the centre of rotation of the hip affects the load and a higher and more medial position will result in greater loads than a lower placement. ${ }^{36,37}$ When the cup is inserted too medially and too high in moderate and severe protrusion the neck will impinge against the acetabular rim, an important factor in loosening, particularly when associated with a thick layer of cement. ${ }^{13}$

Good results have been recorded after reconstruction with bone graft in patients with acetabular protrusion. ${ }^{32,34,35}$ While resorption of graft has been described in areas of substantial weight-bearing, ${ }^{20}$ it is not common when the graft has been used to reconstruct central bone defects in acetabular protrusion. Good results have been reported using a bulk graft to reconstruct acetabular protrusion, ${ }^{4,32}$ but bulk grafts are at risk of mechanical weakening during the process of creeping substitution just at the time when a strong buttress is needed. ${ }^{34,38}$ Compacted bone grafting of the acetabulum with small fragments seems to be a better method because of the rapidity with which a new medial wall regenerates as soon as bone healing has taken place. Animal models and human biopsies have shown that even an allogeneic cancellous graft with cement 
is quickly incorporated into a new trabecular structure. ${ }^{39-42}$ Remodelling continues for at least a year after surgery. In some cases, the iliopectineal line returns almost to normal. The results in our series, and those of other authors, $3,6,32,34,35$ show that the use of other implants to reinforce the acetabulum does not seem justified in primary acetabular protrusion, although they are useful in revision surgery. $^{42}$

Better results were obtained in hips with moderate and severe protrusion reconstructed with spongious bone grafting than in mildly affected hips reconstructed without bone grafting. Reconstruction with bone grafts enables anatomical positioning of the cup and can be recommended in hips with mild acetabular protrusion.

No benefits in any form have been received or will be received from a commercial party related directly or indirectly to the subject of this article.

\section{References}

1. Bayley JC, Christie MJ, Ewald FC, Kelley K. Long-term results of total hip arthroplasty in protrusio acetabuli. J Arthroplasty 1987; 2:275-9.

2. Hastings DE, Parker SM. Protrusio acetabuli in rheumatoid arthritis. Clin Orthop 1975;108:76-84.

3. Heywood AWB. Arthroplasty with a solid bone graft for protrusio acetabuli. J Bone Joint Surg [Br] 1980;62-B:332-6.

4. McCollum DE, Nunley JA, Harrelson JM. Bone-grafting in total hip replacement for acetabular protrusion. J Bone Joint Surg [Am] 1980; 62-A:1065-73.

5. Sotelo-Garza A, Charnley J. The results of Charnley arthroplasty of the hip performed for protrusio acetabuli. Clin Orthop 1978; 132:12-8.

6. Hirst P, Esser M, Murphy JCM, Hardinge K. Bone grafting for protrusio acetabuli during total hip replacement: a review of the Wrightington method in 61 hips. J Bone Joint Surg [Br] 1987; 69-B:229-33.

7. Jefferiss CD, Lee AJC, Ling RMS. Thermal aspects of self-curing polymethylmethacrylate. J Bone Joint Surg [Br] 1975;57-B:511-8.

8. Salvati EA, Bullough P, Wilson PD Jr. Intrapelvic protrusion of the acetabular component following total hip replacement. Clin Orthop 1975;111:212-27.

9. Knight JL, Fujii K, Atwater R, Grothaus L. Bone-grafting for acetabular deficiency during primary and revision total hip arthroplasty: a radiographic and clinical analysis. J Arthroplasty 1993; 8:371-82.

10. Merle d'Aubigné R, Postel M. Functional results of hip arthroplasty with acrylic prosthesis. J Bone Joint Surg [Am] 1954;36-A:451-75.

11. Weissman BN. The radiology of total joint replacement. Orthop Clin North Am 1983;14:171-91.

12. DeLee JG, Charnley J. Radiological demarcation of cemented sockets in total hip replacement. Clin Orthop 1976;121:20-32.

13. Ranawat CS, Dorr LD, Inglis AE. Total hip arthroplasty in protrusio acetabuli of rheumatoid arthritis. J Bone Joint Surg [Am] 1980; 62-A:1059-65.

14. Pagnano MW, Hanssen AD, Lewallen DG, Shaughnessy WJ. The effect of superior placement of the acetabular component on the rate of loosening after total hip arthroplasty: long-term results in patients who have Crowe type-II congenital dysplasia of the hip. J Bone Joint Surg [Am] 1996;78-A:1004-14.

15. Hodgkinson JP, Shelley P, Wroblewski BM. The correlation between the roentgenographic appearance and the operative findings at the bone-cement junction of the socket in Charnley low friction arthroplasties. Clin Orthop 1988;228:105-9.

16. Hodgkinson JP, Maskell AP, Paul A, Wroblewski BM. Flanged acetabular components in cemented Charnley hip arthroplasty: tenyear follow-up of 350 patients. J Bone Joint Surg [Br] 1993; 75-B:464-7.

17. Livermore J, Ilstrup D, Morrey B. Effect of femoral head size on wear of the polyethylene acetabular component. J Bone Joint Surg [Am] 1990;72-A:518-28.
18. Olivier H, Sanouiller JL. Acetabular reconstructions using spongious grafts in reoperation of total hip arthroplasties. Rev Chir Orthop Reparatrice Appar Mot 1991;77:232-40.

19. Meding JB, Ritter MA, Keating EM, Faris PM. Impaction bonegrafting before insertion of a femoral stem with cement in revision total hip arthroplasty: a minimum two-year follow-up study. $J$ Bone Joint Surg [Am] 1997;79-A:1834-41.

20. Gerber SD, Harris WH. Femoral head autografting to augment acetabular deficiency in patients requiring total hip replacement: a minimum five-year and an average seven-year follow-up study. J Bone Joint Surg [Am] 1986;68-A:1241-8.

21. Dorey F, Amstutz HC. Survivorship analysis in the evaluation of joint replacement. J Arthroplasty 1986;1:63-9.

22. Kaplan EL, Meier P. Nonparametric estimation from incomplete observations. J Am Stat Assoc 1958;53:457-81.

23. Christensen E. Multivariate survival analysis using Cox's regression model. Hepatology 1987;7:1346-58.

24. Hosmer DW, Lemeshow S. Applied logistic regression. New York, John Wiley \& Sons, 1989.

25. Kalbfleisch JD, Prentice RL. The proportional hazards model. In: The statistical analysis of failure time data. New York: John Wiley \& Sons, 1980:70-117.

26. Garcia-Cimbrelo E, Munuera L. Early and late loosening of the acetabular cup after low-friction arthroplasty. J Bone Joint Surg [Am] 1992;74-A:1119-29.

27. Garcia-Cimbrelo E, Diez-Vazquez V, Madero R, Munuera L. Progression of radiolucent lines adjacent to the acetabular component and factors influencing migration after Charnley low-friction total hip arthroplasty. J Bone Joint Surg [Am] 1997;79-A:1373-80.

28. Jasty M, Harris WH. Results of total hip reconstruction using acetabular mesh in patients with central acetabular deficiency. Clin Orthop 1988;237:142-9.

29. Poss R, Maloney JP, Ewald FC, et al. Six- to 11-year results of total hip arthroplasty in rheumatoid arthritis. Clin Orthop 1984; 182:109-16.

30. Poss R, Thornhill TS, Ewald FC, et al. Factors influencing the incidence and outcome of infection following total joint arthroplasty. Clin Orthop 1984;182:117-26.

31. Scott RD, Sarokhan AJ, Dalziel R. Total hip and knee arthroplasty in juvenile rheumatoid arthritis. Clin Orthop 1984;182:90-8.

32. Gates HS, McCollum DE, Poletti SC, Nunley JA. Bone-grafting in total hip arthroplasty for protrusio acetabuli: a follow-up note. $J$ Bone Joint Surg [Am] 1990;72-A:248-51.

33. Crowninshield RD, Brand RA, Pedersen DR. A stress analysis of acetabular reconstruction in protrusio acetabuli. J Bone Joint Surg [Am] 1983;65-A:495-9.

34. Kinzinger PJ, Karthaus RP, Slooff TJ. Bone grafting for acetabular protrusion in hip arthroplasty: 27 cases of rheumatoid arthritis followed for 2 to 8 years. Acta Orthop Scand 1991;62:110-2.

35. Slooff TJJH, Huiskes R, van Horn J, Lemmens AJ. Bone grafting in total hip replacement for acetabular protrusion. Acta Orthop Scand 1984;55:593-6.

36. Johnston RC, Brand RA, Crowninshield RD. Reconstruction of the hip: a mathematical approach to determine optimum geometric relationships. J Bone Joint Surg [Am] 1979;61-A:639-52.

37. Yoder SA, Brand RA, Pedersen DR, O'Gorman TW. Total hip acetabular component position affects component loosening rates. Clin Orthop 1988;228:79-87.

38. Mendes DG, Roffmann M, Silbermann M. Reconstruction of the acetabular wall with bone graft in arthroplasty of the hip. Clin Orthop 1984;186:29-37.

39. Roffman M, Silbermann M, Mendes DG. Incorporation of bone graft covered with methylmethacrylate onto acetabular wall: an experimental study. Acta Orthop Scand 1983;54:580-3.

40. Schimmel JW, Buma P, Versleyen D, Huiskes R, Slooff TJ. Acetabular reconstruction with impacted morselized cancellous allografts in cemented hip arthroplasty: a histological and biomechanical study on the goat. J Arthroplasty 1998;13:438-48.

41. Schreurs BW, Buma P, Huiskes R, Slagter JL, Slooff TJ. Morsellized allografts for fixation of the hip prosthesis femoral component: a mechanical and histological study in the goat. Acta Orthop Scand 1994;65:267-75.

42. Slooff TJJH, Schreurs BW, Buma P, Gardeniers JWM. Impaction morcellized allografting and cement. In: Cannon WD Jr, ed. Instructional Course Lectures, Vol. 47. Rosemont, Illinois, The American Academy of Orthopaedic Surgeons, 1998:265-74. 